\title{
Correction for erythroid cell contamination in microassay for immunophenotyping of neonatal lymphocytes
}

\author{
E de Vries, S de Bruin-Versteeg, W M Comans-Bitter, R de Groot, G J M Boerma, \\ F K Lotgering, J J M van Dongen
}

Department of Immunology Erasmus University Rotterdam The Netherlands E de Vries $\mathrm{S}$ de Bruin-Versteeg W M Comans-Bitter J J M van Dongen

\section{Department of} Paediatrics

Bosch Medicentrum Hertogenbosch E de Vries

\section{Department of Paediatrics University Hospital/Sophia Children's Hospital Rotterdam W M Comans-Bitter $\mathrm{R}$ de Groot}

Department of Clinical Chemistry

University Hospital

Rotterdam

G J M Boerma

Department of Obstetrics and Gynaecology

F K Lotgering

Correspondence to: Dr E de Vries

Department of Immunology Erasmus University Rotterdam

PO Box 1738

3000 DR Rotterdam

The Netherlands.

Email:

vandongen@immu.fgg.eur.nl

Accepted 19 October 1998

\begin{abstract}
Immunophenotyping of blood lymphocyte subpopulations in neonates and young infants is hampered by the limited amount of blood that can be collected. Contamination of the flow cytometric "lympho-gate" by normoblasts and analysed erythrocytes, and therefore the underestimation of the relative frequencies of lymphocyte subpopulations, interferes with the precise calculation of absolute counts.

A microassay was developed by adapting the lysed whole blood technique. Triple immunostaining in a single antibody staining step was used to reduce washing steps and cell loss. Introduction of a triple staining for CD71 (expressed by erythroid precursors), glycophorin A (GpA, expressed by all erythroid cells), and CD45 (expressed by all leucocytes) permitted the relative frequencies of normoblasts (CD71 ${ }^{+} / \mathrm{GpA}^{+} / \mathrm{CD}^{-} 5^{-}$population) and unlysed erythrocytes (CD71\%G ${ }^{+} / \mathrm{CD}^{\circ} 5^{-}$ population)to be identified and measured within the "lympho-gate" of neonatal cord blood samples. Particularly high frequencies were found (median: $31 \%$ ) in cord blood samples from preterm neonates. These erythroid cells disappear rapidly by 1 week of age The relative frequencies of erythroid cells can be used to calculate correct lymphocyte subpopulation values. Using only $0.5-0.8 \mathrm{ml}$ of blood, this microassay would also be suitable for rapid prenatal immunodiagnosis of congenital immunodeficiencies.
\end{abstract}

(Arch Dis Child Fetal Neonatal Ed 1999;80:F226-F229)

Keywords: erythroid cell contamination; lymphocyte subpopulations; microassay; normoblasts

Immunophenotyping of blood lymphocyte subpopulations is an important tool in the diagnosis and follow up of children with congenital immunodeficiencies, HIV infection, or other immune disorders. It is also needed for investigation of age related maturational processes within the immune system in childhood. Immunophenotyping of blood lymphocytes used to be performed after density gradient separation, but the lysed whole blood technique is preferred now because it prevents selective cell loss, requires smaller amounts of blood, and results in more accurate determination of absolute lymphocyte counts. ${ }^{1-3}$

In neonates and young infants, several problems are encountered in flow cytometric immunophenotyping of blood lymphocytes. The limited blood volume in these children and technical difficulties in venepuncture restrict the amount of blood that can be collected. In neonates the flow cytometric "lympho-gate" can be contaminated with normoblasts and unlysed erythrocytes (fig 1). Normoblasts are comparable in size and surface membrane to lymphocytes and thus have similar flow cytometric forward scatter (FSC) and side scatter (SSC) characteristics. Neonatal erythrocytes are relatively resistant to osmotic lysis. ${ }^{4}$ Some of them are sufficiently large to collect in the flow cytometric lymphogate. This erythroid cell contamination hampers the determination of the relative frequencies of lymphocyte subpopulations and thus calculation of absolute counts from the total white cell count, which is generally determined as the total nucleated cell count. ${ }^{3}$ In neonates the presence of normoblasts can also interfere with the determination of the total white cell count, because normoblasts are nucleated, and are therefore included in the total count.

To overcome these difficulties, we developed a lysed whole blood microassay with triple immunostaining for the identification of erythroid cells and correction for erythroid cell contamination within the lympho-gate.

\section{Methods}

Twenty one neonatal cord blood samples were collected by venepuncture immediately after clamping of the cord. The blood was kept at room temperature until labelling with monoclonal antibodies was performed within 12 hours of sampling. Peripheral blood was drawn by venepuncture from nine healthy adult volunteers between 20 and 40 years of age, and at 1 week of age from 14 neonates whose cord blood had been studied before. EDTA was used as an anticoagulant.

Informed consent was obtained according to the guidelines of the Medical Ethics Committee of the Erasmus University Rotterdam/ University Hospital Rotterdam in all cases.

The following monoclonal antibodies were used: CD3 (Leu-4a), CD4 (Leu-3a), CD8 (Leu-2a), CD16 (Leu-11c), CD19 (Leu-12), CD56 (Leu-19), CD71 (anti-transferrin receptor), CD45 (HLE1), IgG1 and IgG2 (isotype controls) (Becton Dickinson, San Jose, CA), CD14 (My4), CD19 (B4) (Coulter, Hialeah, FL), CD3 (Hit3a), glycophorinA (GpA) (GAR2), (Pharmingen, San Diego, CA), CD15 (CLBgran2) (Central Laboratory of the Blood 
Transfusion Service, Amsterdam, The Netherlands). All monoclonal antibodies were conjugated with fluorescein isothiocyanate (FITC), phycoerythrin (PE), or the duochrome PECyanin5 (PE-Cy5).

Blood samples $(100,40,20$, or $10 \mu \mathrm{l})$ were incubated with titrated monoclonal antibodies for 10 minutes at room temperature. After two washes with phosphate buffered saline containing $0.1 \% \mathrm{NaN}_{3}$ and $0.5 \%$ bovine serum albumin, erythrocytes were lysed with Lysing Solution (Becton Dickinson) according to the manufacturer's instructions. Before lysis the cell pellet was loosened to prevent incomplete lysis of erythrocytes.

The samples were analysed using a FACScan flow cytometer (Becton Dickinson). Instrument settings were determined with cells labelled with FITC, PE, and PE-Cy5 conjugated monoclonal antibodies and unstained cells. After gating of lymphocytes on the basis of FSC and SSC (checked by CD14, CD15, and CD45 monoclonal antibody staining), 8000 events were acquired. The data were analysed using FACScan software (Becton Dickinson) in dot blots, with optimal quadrant setting checked by histogram analysis, if necessary.

The total nucleated cell count was determined on an $\mathrm{H} 1$ Technicon haemocytometer (Bayer, Tarrytown, NY). The relative frequency of normoblasts was carefully determined by manual differentiation of at least 400 nucleated cells. The total leucocyte count was determined according to the following formula:

total nucleated cell count $\times(100-\%$ of normoblasts $) \times 10^{-2}$

The relative frequencies of lymphocyte subpopulations were calculated according to the following formula:

percentage of population within the lympho-gate $\times 10^{2}$ $\overline{100-\text { (percentage of normoblasts plus percentage of unlysed }}$ erythrocytes within the lympho gate)

The Wilcoxon rank sum test or Friedman's test were used to compare two or more different techniques used in one blood sample, respectively $(\alpha=0.05)$.

\section{Results}

DEVELOPMENT OF MICROASSAY

We incubated $100,40,20$, and $10 \mu \mathrm{l}$ of blood with monoclonal antibodies. When using $20 \mu \mathrm{l}$ of blood, at least 100000 nucleated cells remained available after completion of the staining procedure in all samples tested, as determined by use of a cell counter (Coulter Counter; Hialeah, FL). However, when using $10 \mu \mathrm{l}$ of blood, major and variable cell loss was observed. Relative frequencies of lymphocyte subpopulations determined in parallel with either $100 \mu \mathrm{l}$ or $20 \mu \mathrm{l}$ of blood per test tube gave fully comparable results in five separate neonatal blood samples. Therefore, $20 \mu \mathrm{l}$ of blood incubated with $20 \mu \mathrm{l}$ of each monoclonal antibody per test tube was used in all further experiments.

The determination of the relative frequencies of lymphocyte subpopulations by either double or triple immunostaining was com- pared in one adult and six cord blood samples-for example, triple CD4/CD8/CD3 vs double CD4/CD8, CD4/CD3 and CD8/ CD3 immunostaining. When using triple immunostaining, monoclonal antibodies were either incubated consecutively, with each incubation followed by two washes, or all together. No significant differences were found between the relative frequencies of lymphocyte subpopulations, as determined by the different staining methods. Therefore, in all further experiments only triple immunostaining was used with incubation of all three fluorochrome conjugated monoclonal antibodies simultaneously to speed up the microassay and minimise cell loss due to multiple washes.

DETECTION OF ERYTHROID CELL

CONTAMINATION

When a scatter gate is set around the lymphocyte population, it is generally not possible to exclude fully other contaminating cells without excluding lymphocytes. However, as long as the sum of the relative frequencies of $B$ lymphocytes, $\mathrm{T}$ lymphocytes, and natural killer cells (the so-called "lympho-sum") is at least $95 \%$ (or 0.95), the lympho-gate is often considered to be placed correctly. The remaining events within the lympho-gate are monocytes, granulocytes, and unidentified events, which generally consist of dead cells and debris. In our neonatal cord blood samples the lympho-sum rarely reached $95 \%$ of the lympho-gate (table 1). In preterm neonates, in particular, the lympho-sum seemed to be far too low. This was caused by a relatively high frequency of unidentified events (fig 1).

Normoblasts express CD71 and GpA, whereas erythrocytes express only GpA. In contrast, leucocytes express CD45, unlike normoblasts and erythrocytes. Therefore, $\mathrm{CD}_{71^{+}} /$ $\mathrm{GpA}^{+} / \mathrm{CD} 45^{-}$cells within the lympho-gate can be regarded as normoblasts, whereas unlysed erythrocytes have the $\mathrm{CD} 71^{-} / \mathrm{GpA}^{+} / \mathrm{CD} 45$ immunophenotype. ${ }^{5}$ By triple immunostaining with CD71-FITC, GpA-PE, and CD45-PECy5, these unidentified events could be identified as contamination by normoblasts and in some samples by unlysed erythrocytes as well (fig 2) (table 1). The FSC and SSC of these normoblasts and unlysed erythrocytes was checked ("back-gating"), and was found to be relatively low, as expected for these cells (figs 2C and D).

A small percentage of events remained unidentified - that is, they were neither CD $45^{+}$ leucocytes, nor $\mathrm{CD} 71^{+} / \mathrm{GpA}^{+} / \mathrm{CD} 45^{-}$normoblasts, nor $\mathrm{CD} 71^{-} / \mathrm{GpA}^{+} / \mathrm{CD} 45^{-}$unlysed erythrocytes (left lower quadrant of dot plot in fig 2B). These events may represent dead cells and debris.

ERYTHROID CELL CONTAMINATION IN NEONATAL BLOOD

CD71/GpA/CD45 staining was used to determine the relative counts of normoblasts and unlysed erythrocytes and to calculate the relative counts of lymphocyte subpopulations. The differences in relative frequencies of lymphocyte subpopulations in neonatal cord 


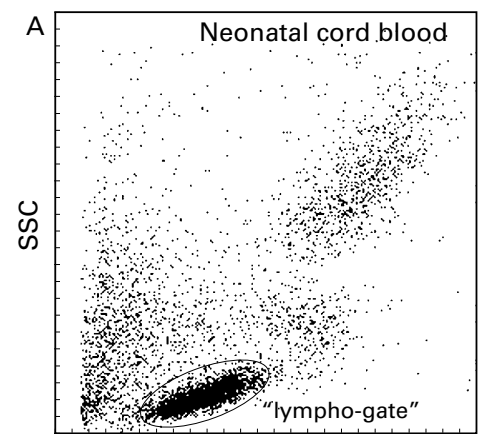

FSC

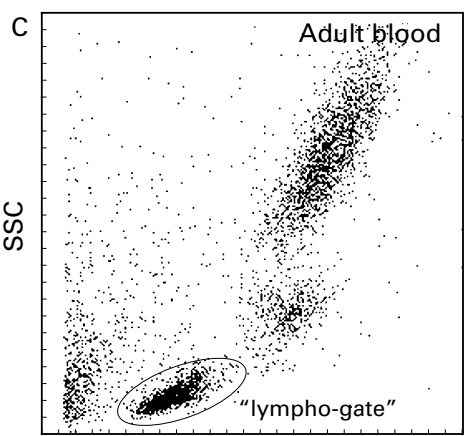

FSC

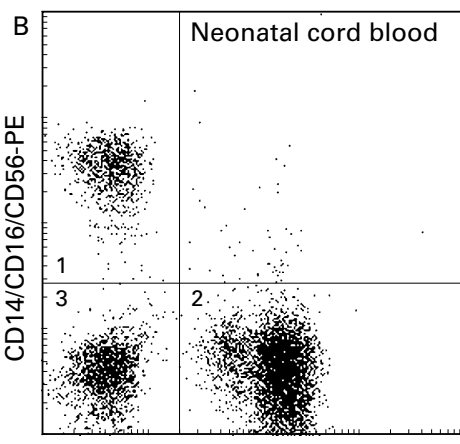

CD3/CD19/CD15-FITC

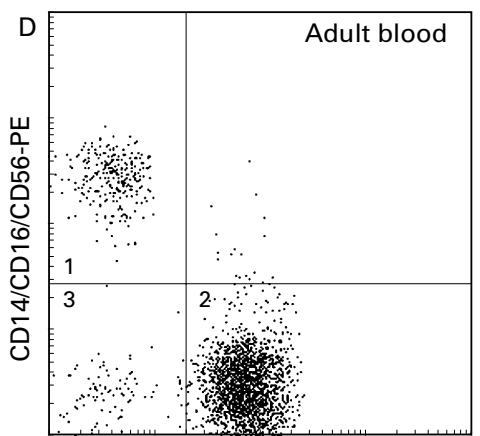

CD3/CD19/CD15-FITC
Figure 1 Flow cytometric immunophenotyping of neonatal cord blood lymphocytes reveals a high frequency of unidentified events within the lympho-gate. (A) Lympho-gate setting in neonatal cord blood, based upon FSC/SSC characteristics. (B) Composition of the lympho-gate in neonatal cord blood: many unidentified events and relatively high numbers of natural killer cells were observed. (C) Lympho-gate setting in adult blood. (D) Composition of the lympho-gate in adult blood: virtually no unidentified events and relatively low numbers of natural killer cells were observed. Quadrant 1: CD14 contaminating monocytes, and $C D 3^{-} / C D 16^{+} / C D 56^{+}$natural killer cells . Quadrant $2: C D 3^{+}$ T lymphocytes, $C D 19^{+} \mathrm{B}$ lymphocytes, and $\mathrm{CD} 15^{+}$contaminating granulocytes. Quadrant 3: Unidentified events. blood with and without a correction for normoblasts and unlysed erythrocytes are shown in table 2 for two samples. Normoblasts were not found by manual differentiation or flow cytometric immunophenotyping in blood samples from the same neonates at 1 week of age nor in blood samples from adults, but unlysed erythrocytes were still present in some samples at 1 week of age (table 1 ).

\section{Discussion}

We have developed a microassay for flow cytometric determination of blood lymphocyte subpopulations in neonates and young infants by adapting the lysed whole blood technique, using one step triple immunostaining. When only double immunostaining is available, more blood is needed and less detailed results are obtained-for example, double positive CD45RA ${ }^{+} / \mathrm{CD}_{45 \mathrm{RO}^{+}} \mathrm{CD}^{+} \mathrm{T}$ lymphocytes cannot be identified. This micro-assay needs only about $0.4 \mathrm{ml}$ of blood to determine $\mathrm{T}$ lymphocyte subpopulations for monitoring HIV infected infants, and 0.5 to $0.8 \mathrm{ml}$ of blood is sufficient for detailed evaluation of infants with suspected congenital immunodeficiencies. Extensive protocols for research purposes can also be performed, because $1.0 \mathrm{ml}$ of blood is sufficient for more than 40 triple immunostainings. These are acceptable volumes in infants and even in preterm babies.

Normoblasts and unlysed erythrocytes can be present in considerable numbers in neonatal samples. ${ }^{4}$ The presence of normoblasts cannot be prevented by technical measures, but strict adherence to a rigorous lysing protocol can minimise the number of unlysed erythrocytes in a sample. Therefore, identification of both cell populations is of interest. Using triple

Table 1 Composition of "lympho-gate" in neonatal and adult blood samples*

\begin{tabular}{|c|c|c|c|c|c|c|c|c|c|c|c|c|}
\hline \multirow[b]{2}{*}{ Lympho-gate populations } & \multicolumn{3}{|c|}{ Preterm neonates $(n=6)$} & \multicolumn{3}{|c|}{ Term neonates $(n=15)$} & \multicolumn{3}{|c|}{$\begin{array}{l}\text { The same neonates at one week } \\
\text { of age (one preterm and } 13 \\
\text { term neonates) }\end{array}$} & \multicolumn{3}{|l|}{$\begin{array}{l}\text { Adults } \\
(n=9)\end{array}$} \\
\hline & Mean & Median & Range & Mean & Median & Range & Mean & Median & Range & Mean & Median & Range \\
\hline Lympho-sum $\dagger$ & 57 & 61 & $24-78$ & 85 & 86 & $67-95$ & 95 & 96 & $92-98$ & 98 & 98 & $97-100$ \\
\hline $\mathrm{CD}_{1} 4^{+}$monocytes & 2 & 2 & $1-2$ & 1 & 1 & $0-3$ & 1 & 1 & $0-2$ & 1 & 1 & $0-2$ \\
\hline $\mathrm{CD} 15^{+}$granulocytes & 1 & 1 & $0-1$ & 1 & 1 & $0-1$ & 1 & 1 & $0-1$ & 0 & 0 & $0-1$ \\
\hline $\mathrm{CD} 71^{+} / \mathrm{GpA}^{+} / \mathrm{CD} 45^{-}$normoblasts & 31 & 29 & $8-57$ & 10 & 7 & $3-28$ & 0 & 0 & $0-1$ & 0 & 0 & $0-0$ \\
\hline $\mathrm{CD} 71^{-} / \mathrm{GpA}^{+} / \mathrm{CD} 45^{-}$unlysed erythrocytes & 4 & 3 & $2-5$ & 2 & 1 & $0-11$ & 2 & 1 & $0-8$ & 1 & 1 & $0-2$ \\
\hline
\end{tabular}

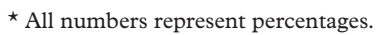

† Lympho-sum $=\mathrm{CD} 19^{+}+\mathrm{CD}^{+}+\mathrm{CD}^{-} \mathrm{CD} 16 / 56^{+}(\mathrm{B}+\mathrm{T}+\mathrm{NK})$ without correction for the erythroid cell contamination of the lympho-gate

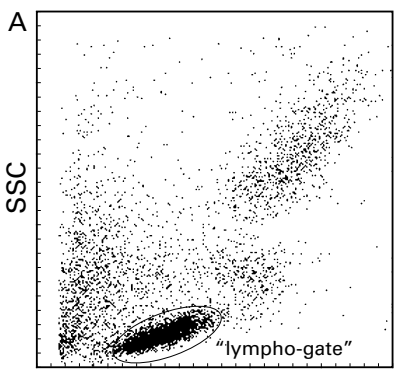

FSC

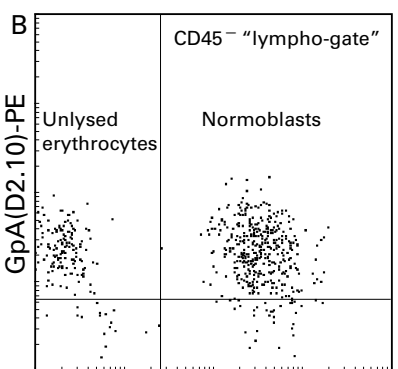

CD71(66IG10)-FITC

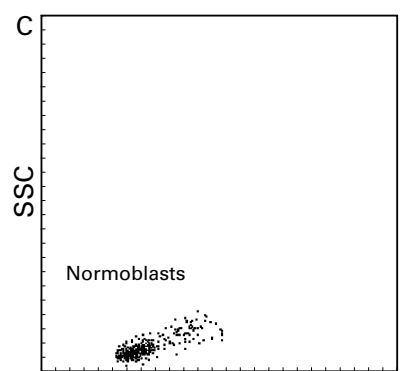

FSC

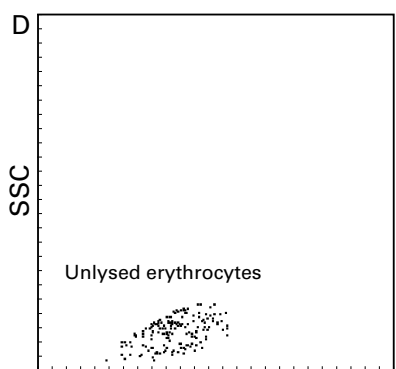

FSC

Figure 2 Triple staining for $C D 71, G p A$, and CD45 identifies normoblasts and unlysed erythrocytes within the lympho-gate. (A) Lympho-gate setting. (B) $C D 71^{+} / G p A^{+} / C D 45^{-}$population of normoblasts and the $C D 71^{\prime} / G p A^{+} / C D 45^{\circ}$ population of unlysed erythrocytes within the CD $45^{\circ}$ lympho-gate. (C) Back-gating of $C D 71^{+} / G p A^{+} / C D 45^{-}$normoblasts into the lympho-gate. (D) Back-gating of and $C D 71^{-} / G p A^{+} / C D 45^{-}$unlysed erythrocytes into the lympho-gate. 
Table 2 Illustration of erythroid cell contamination bias in two cord blood samples *

\begin{tabular}{|c|c|c|c|c|c|c|c|c|c|c|}
\hline \multirow[b]{2}{*}{ Gestational age } & \multicolumn{2}{|c|}{$\begin{array}{l}\text { Erythroid cells within } \\
\text { "lympho-gate" }\end{array}$} & \multicolumn{2}{|c|}{$C D 3^{+}$T lymphocytes } & \multicolumn{2}{|c|}{ CD1 $19^{+}$B lymphocytes } & \multicolumn{2}{|c|}{$\begin{array}{l}C D 3^{-} C D 16 / 56^{+} \text {natural } \\
\text { killer cells }\end{array}$} & \multicolumn{2}{|l|}{ Lympho-sum } \\
\hline & Normoblasts & Unlysed & Uncorrected $\dagger$ & Corrected $\ddagger$ & Uncorrected $\dagger$ & Corrected $\neq$ & Uncorrected $†$ & Corrected $\neq$ & Uncorrected $\dagger$ & Corrected $\neq$ \\
\hline 29 weeks & 44 & 5 & 28 & 54 & 18 & 36 & 10 & 20 & 56 & 110 \\
\hline 35 weeks & 40 & 3 & 24 & 43 & 10 & 17 & 17 & 30 & 51 & 89 \\
\hline
\end{tabular}

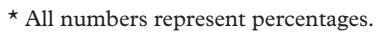

† Without correction for the erythroid contamination of the lympho-gate.

$\ddagger$ With correction for the erythroid contamination of the lympho-gate.

immunostaining for CD71, GpA, and CD45, we were able to identify both normoblasts $\left(\mathrm{CD} 71^{+} / \mathrm{GpA}^{+} / \mathrm{CD} 45^{-}\right.$cells) and unlysed erythrocytes $\left(\mathrm{CD}^{2} 1^{-} / \mathrm{GpA}^{+} / \mathrm{CD} 45^{-}\right.$cells) within the lympho-gate, and to measure their relative frequencies. When only double immunostaining is available, $\mathrm{GpA}^{+} / \mathrm{CD} 45^{-}$cells can be used to measure the relative frequency of erythroid cells, but normoblasts and unlysed erythrocytes cannot be identified separately. The relative frequencies of erythroid cells can be used to calculate the correct relative frequencies of blood lymphocyte subpopulations. This is especially important in preterm neonatal and prenatal blood samples, where the relative frequencies of normoblasts and unlysed erythrocytes can be high (tables 1 and 2), ${ }^{6}$ and the frequencies of lymphocyte subpopulations can be underestimated. This can be confusing if a congenital immunodeficiency is suspected. The erythroid cell contamination of the lympho-gate rapidly disappears after birth and is virtually absent by 1 week of age (table 1 ).

In conclusion, we have developed a fast and easy to use lysed whole blood microassay for immunophenotyping of neonatal and infant blood lymphocyte subpopulations. It requires only a small volume of blood $(20 \mu \mathrm{l}$ per test tube), and offers a method to correct for the presence of normoblasts and unlysed erythrocytes in neonatal samples. It would also be suitable for rapid prenatal immunodiagnosis of congenital immunodeficiencies when genetic markers are not available. ${ }^{7}$

1 Remy N, Oberreit M, Thoenes G, Wahn U. Lymphocyte subsets in whole blood and isolated mononuclear leukocytes of healthy infants and children. Eur $\mathcal{f}$ Pediatr 1991;150:230-3.

2 Kutvirt SG, Lewis SL, Simon TL. Lymphocyte phenotypes in infants are altered by separation of blood on density gradients. Br F Biomed Sci 1993;50:321-8.

3 Comans-Bitter WM, De Groot R, Van den Beemd MWM, Neijens HJ, Hop WCJ, Groeneveld K, Hooijkaas H, Van Dongen JJM. Immunophenotyping of blood lymphocytes in childhood: Reference values for lymphocyte subpopulations. F Pediatr 1997;130:388-93.

4 Oski FA. The erythrocyte and its disorders. In: Nathan DG, Oski FA, eds. Hematology of infancy and childhood. Philadelphia: W B Saunders, 1993:18-43.

5 Loken MR, Shah VO, Dattilio KL, Civin CI. Flow cytometric analysis of human bone marrow: I. Normal erythroid ric analysis of human bone marrow:

6 Letsky EA. Appendix I: Haematological values in the newborn. In: Roberton NRC, ed. Textbook of neonatology. Edinburgh: Churchill Livingstone, 1992:1231

7 WHO Scientific Group. Primary immunodeficiency diseases. Clin Exp Immunol 1995;99(S1.2):1-24. 